\title{
NOTAS
}

\section{La diversidad etnológica y alimentaria en la encrucijada de la conservación y el desarrollo}

\section{INTRODUCCIÓN}

En nuestra América, la diversidad vegetal y étnica, en íntima comunidad, ha aportado a la cultura alimentaria recursos que hoy en día resul$\tan$ insustituibles en la dieta humana. A su vez, estas sociedades en su devenir histórico han incorporado plantas exógenas, que forman también parte de su alimentación y desarrollo. Sin embargo, hay que remarcar que en la América tropical este flujo de recursos fitogenéticos se ha ido deteniendo, debido, fundamentalmente, al embate que han sufrido desde los tiempos prehispánicos los distintos ecosistemas, así como a la constante erosión de las etnias y comunidades campesinas.

$\mathrm{Si}$ este deterioro no se detiene, se verán amenazados los recursos necesarios para seguir enriqueciendo la variedad de la alimentación mundial. Por lo que es indispensable, por un lado, conservar los recursos en el sentido de uso sustentable y, por el otro, luchar por la no destrucción y el respeto a la cultura alimentaria de las poblaciones. Estas dos premisas básicas son parte esencial en la revitalización y continuidad de este flujo, que fue el que aportó al mundo uno de los tesoros más preciados, un sin número de plantas alimentarias.

La enorme transformación del medio natural y del marco social de los pueblos americanos a partir de la conquista ha conllevado cambios profundos. Cuando los quisimos sintetizar para presentarlos como enunciados, nos encontramos ante una tarea realmente intrincada, primordialmente por los tópicos tan disímbolos y complejos que encierran. Sin embargo, hicimos un intento arriesgado, porque creímos que no debía faltar para la comprensión de esta gran encrucijada un marco de referencia históricoecológico, sobre todo hoy en día, en que la cultura del poder reclama ahistoricidad.

Las formulaciones a las que llegamos y que nos parecieron las más significativas fueron las catorce siguientes:

1. Extinción de numerosas etnias y de sus memorias gráficas.

1 Trabajo presentado al XIII Congreso Internacional de Antropología. México, 1993. 
2. Imposición de una religión monoteísta (la católica) sobre la politeísta vigente.

3. Reducción de la población indígena a través de guerras, epidemias, hambrunas y extenuación.

4. Exclusión de las estructuras políticas y económicas.

5. Destrucción o al menos profunda alteración de la organización social.

6. Desestabilización de algunos ecosistemas (desforestación de bosques y selvas) para la creación de potreros (pastizales).

7. Establecimiento y predominio de la reinante cultura europea del animal, sobre la preexistente cultura amerindia del vegetal.

8. Introducción de una flora y fauna utilitaria propia de la cultura europea.

9. Reducción de las áreas de los cultivos autóctonos presentes en detrimento de su producción.

10. Transposición de una tecnología agrícola ajena y por demás nociva a los suelos y a la vegetación tropical americana.

11. Apropiación del recurso fitogenético y de algunas técnicas indígenas, pero simultáneamente irrespeto y desdén a las culturas sustentadoras de este saber.

12. Modificación de los patrones culturales alimentarios y de salud, así como de los conceptos sobre la vida y la muerte.

13. Dislocación de las concepciones sobre la naturaleza, la estética, la arquitectura, las artes, la música, la indumentaria, las armas, el comercio, el transporte y las comunicaciones.

14. Obligatoriedad de la lengua castellana en detrimento de las lenguas parlantes.

Todos estos elementos han estado presentes en el cuadro de la gran aportación del germoplasma vegetal con que América desde 1492 comenzó a obsequiar a la cultura alimentaria mundial. Esta donación no fue, como se nos ha enseñado, una simple transportación de raíces, tubérculos, frutos o semillas de un continente a otro, sino la apropiación de uno de los más elaborados productos de una cultura, como es: la domesticación y la conservación fitogenética. El resultado de estos dos procesos demuestra un profundo conocimiento de la naturaleza y un acucioso y paciente trabajo humano, que desembocó en el cultivo de plantas silvestres, hace nada menos que 7.000 años. A guisa de ejemplo están: el aguacate (Persea americana); el maíz blanco, amarillo, azul o prieto y el colorado (Zea mays); cuatro especies de calabazas (Cucurbita pepo, C. moschata, C. maxima, C. ficifolia); el chile o ají (Capsicum annuum) y la papa 
(Solanum tuberosum). Asimismo, estas poblaciones domesticaron hace 5.000 a 3.000 años dos especies de frijoles (Phaseolus vulgaris, $P$. coccineus); la yuca o huacamote (Manibot esculentum); el tomate (Physalis ixocarpa); el jitomate o tomate (Lycopersicum esculentum); el camote o boniato (Ipomoea batatas); el nopal (Opuntia ficusindica); el cacahuete (Arachis hypogaea)... y muchos más.

La incorporación gradual y luego intensa de estas plantas no sólo logró la variación y enriquecimiento de la dieta europea, sino que también cambió hábitos y costumbres sociales y condicionó el desarrollo de nuevas y muy prósperas industrias. El nuevo comercio con América llegó a niveles de importancia económica nunca antes vistos. Desafortunadamente, el reconocimiento de este magnífico aporte nunca se ha hecho patente, por lo cual las sociedades cuya milenaria cultura fue el origen han resultado hasta ahora ignoradas. Para tener una idea de la magnitud de esta contribución a la cultura alimentaria mundial, bastaría imaginar la comida actual si se tuviera que prescindir de: el cacao, la vainilla, la papa, el tomate o jitomate, los frijoles o judías, el chile o pimiento, el aguacate, la calabaza, la yuca o huacamote, el camote o boniato, los ejotes o judías verdes, el girasol, la papaya, las anonas, la piña... y muchos más. Estas plantas aportaron sabores nuevos y colores que transformaron los aspectos estéticos de muchos alimentos, por ejemplo, los grises embutidos gracias al chile, elaborados con "pimentón", se tornaron rojizos, haciendo más atractiva su presencia, al igual que en los pasteles la introducción del aroma de la vainilla y el color del chocolate los volvió más apetitosos.

El flujo de plantas alimentarias desde América, que alcanzó un extraordinario nivel en los siglos XVI y XVII, ha ido perdiendo ritmo hasta nuestros días y no solo porque, lógicamente, cada vez resulta más difícil encontrar una especie comestible no conocida, sino también por el acelerado deterioro del medio natural del continente americano; la tala indiscriminada, el menosprecio por los valores culturales de sus pueblos, las presiones sociales que reducen cada vez más las áreas de cultivo de subsistencia y las políticas agrícolas a nivel internacional, son algunos de los factores que han limitado este flujo.

Sin embargo, el conocimiento campesino o indígena actual sobre recursos comestibles incluye, además de los ya cultivados desde antaño, otros en pleno proceso de domesticación y los silvestres de sus ecosistemas circundantes. Todo ello constituye una diversidad biológica nada despreciable y una esperanza en la ampliación de la dieta en el mundo de hoy. Una pequeña muestra de esta gran diversidad de plantas de origen americano que no ha penetrado la alimentación internacional es la siguiente: entre las raíces tenemos la jícama (Pachyrrisus erosus); frutos de clima 
templado como el capulin (Prunus capuli), el tejocote (Crataegus mexicana); frutos de origen tropical como el mamey (Mamea americana), el chicozapote (Akras zapota), la chirimoya (Annona cherimola), la guanábana (Annona muricata), el zapote negro (Diospyrus ebenaster), el tomate de cáscara (Physalis ixocarpa), el guaje (Leucaena esculenta), el huauzontle (Quenopodium nutalie), los romeritos (Dondia torrellena). Para aromatizar, el epazote (Quenopodium ambrosoides), el pápalo (Porophyllum macrocephallum), el acuyo u hoja santa (Piper auritum), y para dar un giro espectacular a la dieta, la introducción de flores: flor de calabaza (Cucurbita pepo), flor de izote (Yuca flifera), flor de Tzonpantlí, colorín o gasparitos (Erithrina americana), flor de ayocote (Phaseolus coccineus).

Otras causas que han detenido el flujo de plantas hay que buscarlas en el contexto socio-político de cada época. Así, el caso del huautli o amaranto (Amaranthus bipocondriacus) cuyo cultivo fue proscrito y activamente combatido por las autoridades religiosas durante la conquista de México. Su germoplasma quedó conservado por grupos sociales apartados correspondientes a diferentes etnias, pudiendo ser rescatado y actualmente reconocido como el alimento vegetal que mayor riqueza de aminoácidos esenciales puede brindar a la alimentación humana. Las leyes del mercado, ciegas a las realidades de la diversidad biológica y a la conservación, han terminado por ajustar la dieta a unas pocas especies (alrededor de 70). Con ello se contribuye a poner en riesgo muchos recursos vegetales, al no encontrar para ellos un espacio económico viable.

Todos estos procesos y otros están propiciando la merma de los recursos fitogenéticos y lo que es más grave, están erosionando la memoria milenaria de su uso y manejo, siendo incalculable lo que significa para la humanidad perder estos recursos y la información sobre ellos. La importación de modelos de explotación agrícola y tenencia de la tierra, condicionados por las sociedades que en América se han ido desarrollando, ha conducido del policultivo al monocultivo; del mantenimiento de recursos sostenibles a las prácticas no sustentables; de la coexistencia con el entorno vegetal a la eliminación irracional de la vegetación; del uso de recursos autóctonos a la importación de recursos foráneos y de la alimentación con base esencialmente vegetal a la alimentación principalmente carnívora. Todo eso ocurre en paralelo con un proceso de transculturación, que no sería tan grave si no conllevara la desvalorización de la riqueza cultural de las sociedades latinoamericanas. Todo proceso de conservación de los recursos fitogenéticos alimentarios debe contemplar la revalorización del saber de la sociedad cuya cultura tradicional lo ha sostenido, no puede concebirse la conservación del medio sin la conservación de los pueblos. Hay que luchar por valores culturales que partiendo de la pro- 
pia realidad americana propicien un acercamiento a la naturaleza americana.

Por otra parte, no sería justo omitir el significado que ha tenido la introducción de especies comestibles desde otras partes del mundo a nuestra América y, por solo citar alguna, están: la caña de azúcar, café, arroz, trigo, soja, el olivo, vid, mango, cítricos y el plátano. Algunos de estos productos han sido la base de los monocultivos y del desastre ecológico de algunas regiones, pues la tala de los bosques para la implantación de las grandes plantaciones bananeras y cafetaleras en Centroamérica es un problema actual, como lo fue el desmonte de grandes áreas para el cultivo de la caña de azúcar en el Caribe. Pero más grave aún fue y sigue siendo el desmonte para la implantación de modelos primitivos de ganadería extensiva, proceso que de los llanos se ha ido trasladando a las sierras, ocasionando el lavado y erosión de los suelos, o cuando se pretende implantar en selvas donde los escasos nutrientes son arrastrados y se abren espacios a la desertización.

Está claro entonces que a la naturaleza americana le pueden ser propios solo modelos de explotación de la tierra que permitan un desarrollo sostenible o nos quedamos sin tierras cultivables. Los pueblos americanos practicaron, y en varias regiones aún utilizan, tecnologías que permiten la explotación de la tierra sin daños tan graves, como son las chinampas, la milpa y otras prácticas que, si bien no pueden dar soluciones a los actuales problemas, pueden servir de base para el perfeccionamiento de nuevas tecnologías. Hoy en día siguen siendo reserva de fitoplasma y de diversidad alimentaria espacios de concepción prehispánica entre los que se encuentran los huertos familiares, los conucos, la milpa... y otros modelos en los que afortunadamente los campesinos mantienen variedades, formas semidomesticadas y la experimentación constante con plantas silvestres. Los sistemas socioeconómicos y políticos que se desarrollen, deberán tener en cuenta la diversidad cultural y alimentaria que existe local y regionalmente para que las diversas formas de tenencia de la tierra y la conservación de los fitorrecursos alimentarios puedan seguir perdurando y las comunidades que los sustentan alcancen una mejor calidad de vida y un reconocimiento como conservadores y experimentadores de estos recursos.

A las instituciones científicas que abordan estos problemas, como son los bancos de germoplasma, instituciones abocadas a la reforestación, a la educación ambiental y a la conservación, se les sugiere poner en un papel protagónico a los campesinos, detentadores de la sabiduría alimentaria, de los ecosistemas naturales y agrícolas donde viven. Para los planes de reforestación, aún insuficientes, se debería hacer hincapié en la siembra 
de fitorrecursos autóctonos, que comprendan más de una categoría de uso, por ejemplo alimentario, medicinal, ornamental maderable, melífero, etc., para que en un menor espacio se puedan reunir todos los satisfactores mencionados. Para las instituciones públicas, como los jardines botánicos, se debe considerar loable la inclusión de colecciones de plantas alimentarias con sus variedades, formas semidomesticadas y parentales silvestres, y la demostración de los conocimientos tradicionales de las comunidades de donde provienen esos fitorrecursos. Solo teniendo en cuenta estos factores, puede lograrse la educación ambiental que ayude a la conservación de la diversidad alimentaria in situ y ex situ.

Para finalizar, podemos expresar que la cultura alimentaria debe formar parte de la base de la pirámide, que pretende alcanzar el rescate y conservación de la diversidad de fitorrecursos de los pueblos americanos y su desarrollo sostenido.

MONTSERRAT Gispert CRUELLS

Área de Etnobotánica. Facultad de Ciencias

UNAM. México D. F.

ALBERTo Álvarez DE ZAYAS

Instituto de Ecología y Sistemática Academia de Ciencias de Cuba. La Habana 